entirely satisfied with the quality and extent of the information at its disposal. This was reflected in its decision to pursue three lines of investigation. Firstly, a prospective study was undertaken under the auspices of the Public Health Laboratory Service in association with the Communicable Diseases (Scotland) Unit to assess the degree of hazard which whoopingcough infection presented to children. The Public Health Laboratory also undertook actively to investigate the efficacy of pertussis vaccine. Lastly, a new subcommittee was appointed to review information on the risks of immunisation.

A year later, in June 1975, the Joint Committee had received new information from all three sources. ${ }^{3}$ The Public Health Laboratory Service reported that whooping cough was still a severe disease in children, particularly in those under 1 year old. It also provided evidence that current vaccines gave a high degree of protection. Though the subcommittee on complications of vaccination could not then assess the precise risk associated with vaccination, it was satisfied that the hazards to children from whooping cough exceeded those of immunisation. The committee unanimously agreed that on the evidence now available the policy of offering pertussis vaccine in infancy should not be changed. Its members had satisfied themselves that allegations of lack of efficacy and high risk of severe after effects had been somewhat exaggerated, though the committee did not offer any information on the effect, or the consequences, of the adverse and widespread publicity given to those allegations.

The pertussis vaccination programme developed gradually in England and Wales during the 1950's, until by 1960 all but one local health authority had approved arrangements for immunisation. Before the programme had got under way there were about 120000 to 150000 notifications of whooping cough every year, but by 1957 the effect of routine immunisation of infants began to have an effect on notifications. A three-year periodicity in epidemics appeared, and each epidemic was less than the previous one. The number of children contracting the disease during the first year of life, when they are most vulnerable to severe complications, also decreased in proportion to the total number of notifications, which was only 20000 for the three years 1972-4.

Children aged under 12 months consistently account for 10 to $12 \%$ of the total notifications, and another half of all notifications consist of children between 1 and 4 years of age. A sharp decrease in the number of infants routinely immunised after the 1974 adverse publicity could mean that there will be a substantial pool of susceptible children when the next epidemic is due in 1978. Will this mean that there will then be a resurgence of whooping cough ?

In a recent review of the present status of pertussis immunisation $^{4}$ it was reported that pertussis vaccine was highly effective. The risk it carries of inducing or precipitating a serious reaction is substantially less than claimed a year ago. It may possibly be as high as 1 in 100000 but perhaps as low as 1 in 1 million. The experts are almost unanimous in recommending the use of pertussis vaccine routinely except in certain defined conditions. It is easy to forget the damage done to infants by whooping cough, even now that antibiotics are available: it would be disastrous to allow this risk to occur again.

1 Kulenkampff, M, Schwartzman, J S, and Wilson, J, Archives of Disease in Childhood, 1974, 49, 46.

${ }^{2}$ Chief Medical Officer, Department of Health and Social Security, letter $17 / 74$ to General Practitioners, Regional Medical Officers and Area Medical Officers, 11 June 1974.

${ }^{3}$ Joint Committee on Vaccination and Immunisation of the Central Health Services Council and the Scottish Health Service Planning Council, British Medical fournal, 1975, 3, 687.

4 Edsall, G, Practitioner, 1975, 215, 310.

\section{Mental health in developing countries}

When in 1913 Schweitzer $^{1}$ went to Lambarene he observed that mental complaints were rarer there than in Europe. But even then in the Congo, as elsewhere, there certainly were mentally ill persons-though summary but perhaps necessary measures of disposal may have kept their numbers down.

Subsequently, studies such as those of Field, ${ }^{2}$ who showed that the prevalence of schizophrenia in rural Ghana was virtually identical with that in Western Europe, left no doubt that the inhabitants of developing countries were not immune from mental illness; nor, as Lewis $^{3}$ stated in his opening address to the first Pan-African Psychiatric Conference in 1961, was there any convincing evidence that the incidence of mental illness was any different in Africans than in Europeans. The same is true elsewhere in the world, and the WHO Expert Committee on Mental Health ${ }^{4}$ has estimated recently that over 40 million people in developing countries currently suffer from serious untreated mental disorders.

What emerges so clearly from this report is that it is development itself which tends to bring mental disorder to light. When other more pressing needs have first to be met-such as adequate nutrition and water supplies and the control of infectious diseases-mental health problems, while they may nag in the background, may not excite immediate concern. Once physical deprivations have been conquered, or even partly so, and overall standards of living have begun to rise then mental illness begins to loom larger. But there is no need to travel overseas to discover this: it is amply evident in the history of social development in Western Europe during the last 200 years. The process of civilisation, indeed, contains forces which operate adversely on mental health, some uncovering what is lying dormant, while others may actually be pathogenic, such as overurbanization, the disintegration of family life, and increasing social isolation. Furthermore, as the physical health of a nation improves and longevity increases the prevalence of psychiatric disorders of old age inevitably rises.

Not only is the prevalence of mental disorders in developing countries of the same order as that here at home, but they appear to be largely similar in range and type, though cultural factors are known to modify content. This resemblance is particularly true of the major functional psychoses and possibly somewhat less so in the case of neurotic or personality problems. Even then, the WHO Committee states that such disorders are no less common or troublesome in developing countries-their prevalence may be as high as $10 \%$ or more in the population at large and higher still among those seeking help from curative services.

In listing the measures necessary to cope with this increasing burden, all the old and over-familiar needs at once become evident-the need to alter attitudes towards the mentally ill, the need for resources of very many different kinds, and above all the need for the scarcest commodity of all-skilled hands. Whereas at one time the traditional "healer" fulfilled a useful function in treating milder mental illnesses within the setting of a village community, this time has passed. The inhabitants of developing countries have as much right of access as others to such skills as 20th century psychiatry can offer.

There is, however, the important possibility of a second chance. The history of Western psychiatry is littered with mistakes; those concerned with promoting mental health in the Third World, given hindsight, may not need to repeat these errors. One example cited by the WHO Expert Commit- 
tee is the creation of large mental hospitals having a primarily custodial function, which has been shown to be no answer and should be discouraged. A hopeful sign is that the emphasis in this report, though not eschewing treatment, has moved towards prevention-in which ultimately there must lie much greater profit.

1 Schweitzer, A, On the Edge of the Primeval Forest. London, Black, 1948.

2 Field, M J, Search for Security, An Ethnopsychiatric Study of Rural Ghana. London, Faber and Faber, 1960.

3 Lewis, A, in Report of the First Pan-African Psychiatric Conference, ed. T A Lambo, Ibadan, 1961.

4 World Health Organisation, Organisation of Mental Health Services in Developing Countries. 16th Report of the WHO Expert Committee on Mental Health, Geneva, WHO, 1975.

\section{Prolactin, pregnancy, and lactation}

There are two distinct phases of lactation; milk secretion, the synthesis of milk within the mammary alveolar cells and its excretion into the alveolar lumen; and milk ejection, the transfer of the secreted milk into the larger ducts and sinuses, where it is obtainable by suckling. ${ }^{1}$ The first phase is dependent on the anterior pituitary hormone prolactin and the second on oxytocin released from the posterior pituitary. Prolactin is normally under inhibitory control from the hypothalamus, and recent evidence suggests that the prolactin inhibitory factor is not a polypeptide similar to the hypothalamicreleasing hormones but is dopamine itself. ${ }^{2}$ Recently, interest in this first phase of milk secretion has been stimulated by the development of a specific radioimmunoassay for prolactin $^{34}$ and the introduction of bromocriptine, ${ }^{5}$ a dopaminergic drug which inhibits prolactin secretion.

Prolactin has been shown to enhance the production of specific enzymes concerned in the synthesis of milk protein ${ }^{6}$ and lactose, ${ }^{7}$ and it may also affect the production of nucleic acids. $^{8}$ In pregnancy the prolactin level becomes raised by the eighth week of gestation and rises steadily to term. If the woman does not breast feed it returns to normal within two to three weeks of delivery. ${ }^{9}$ This rise in prolactin, which is of pituitary origin, is paralleled by an increase in placental production of a similar hormone, human placental lactogen (HPL). Both hormones are lactogenic; nevertheless, little or no lactation occurs before parturition, because increased levels of ovarian and placental steroids block their peripheral actionsas was first suggested by the classic experiments of Lyons ${ }^{10}$ and Nandi ${ }^{11}$ in hypophysectomised rats and mice. They showed that lobuloalveolar proliferation could be induced by a combination of oestrogen, progesterone, prolactin, growth hormone, and adrenal corticoids and that milk secretion could then be initiated by continuing the injections of prolactin and corticoids while stopping those of the ovarian hormones and growth hormone. Further indirect evidence was obtained by Brun et $a l,{ }^{12}$ who found that in patients in the postpartum period prolactin levels fell immediately after administration of bromocriptine and that this decrease was associated with lack of milk formation. Patients treated with a standard oestrogen preparation also did not lactate, though serum prolactin levels remained raised.

The relation between the raised prolactin levels and puerperal amenorrhoea is still disputed. Evidence exists for a direct action of prolactin on the ovaries, for high levels inhibit progesterone synthesis in vitro. ${ }^{13}$ An action on the hypothala- mus or pituitary has also been suggested, since puerperal women have low basal FSH levels, which rise as prolactin falls during treatment with bromocriptine. ${ }^{14}$

When bromocriptine is generally available it will be useful in the suppression of lactation, ${ }^{15}$ for oestrogen therapy is associated with a $12 \%$ failure rate ${ }^{16}$ and a risk of thromboembolism, ${ }^{17}$ while diuretics are ineffective when given alone. ${ }^{16}$

Human prolactin secretion may be stimulated by thyrotrophin-releasing hormone $(\mathrm{TRH})^{18}$ and several drugsincluding the phenothiazines, rauwolfia alkaloids, imipramine, haloperidol, methyldopa, metoclopramide, and high doses of oestrogens. TRH is probably not important in the physiological regulation $^{19}$ of prolactin secretion but a rise in endogenous prolactin secretion in postpartum women using this hormone is associated with an increase in milk production and milk fat composition. ${ }^{20}$ However, there appears to be little therapeutic use for such drugs in the stimulation of prolactin production.

1 Cowie, A T, Proceedings of the Royal Society of Medicine, 1972, 65, 1084.

2 Schally, A V et al, Federation Proceedings, 1974, 33, 237.

3 Bryant, G D, et al, Hormones, 1971, 2, 139.

4 Hwang, P, Guyda, H, and Friesen, H, Proceedings of the National Academy of Sciences of the USA, 1971, 68, 1902.

${ }^{5}$ Lutterbeck, P, et al, British Medical fournal, 1971, 3, 228.

6 Turkington, R W, fournal of Clinical Endocrinology and Metabolism, 1971, 33, 210.

7 Turkington, R W, et al, fournal of Biological Chemistry, 1968, 243, 3382.

${ }^{8}$ Convey, E M, et al, fournal of Dairy Sciences, 1973, 56, 484.

9 Tyson, J E, et al, American fournal of Obstetrics $\mathbb{E}$ Gynecology, 1972, 113, 14.

${ }^{10}$ Lyons, W R, Li, C H, and Johnson, R E, Recent Progress in Hormone Research, 1958, 14, 219.

11 Nandi, S, University of California Publications in Zoology, 1959, 65, 1.

12 Brun del Re, R, et al, Obstetrics and Gynecology, 1973, 41, 884.

${ }_{13}$ McNatty, K P, Sawyers, R S, and McNeilly, A S, Nature, 1974, 250, 653.

14 Nader, S, et al, British Fournal of Obstetrics and Gynaecology. In press.

15 Rolland, R, and Schellekens, L, fournal of Obstetrics and Gynaecology of the British Commonwealth, 1973, 80, 945.

16 Hodge, C, Lancet, 1967, 2, 286.

17 Daniel, D G, Campbell, H, and Turnbull, A C, Lancet, 1967, 2, 287.

18 Bowers, C Y, et al, Biochemical and Biophysical Research Communications, $1971,45,1033$.

19 Malarkey, W B, and Beck, P, fournal of Clinical Endocrinology and Metabolism, 1975, 40, 708.

20 Tyson, J E, et al, fournal of Clinical Endocrinology and Motabolism, 1975, 40, 764 .

\section{Facile mutagenesis by hair dye constituents}

Several highly sensitive techniques based on the use of microorganisms have been developed for detecting mutagenic activity. The hall-mark of such systems is that the changes that occur do so with great facility. Those who use such tests claim that, since known carcinogens give positive results, any other substance of unknown carcinogenic potential which does so should also be suspected of carcinogenicity or even regarded as carcinogenic until proved otherwise.

At the cellular level, it is likely that any mutation-like change that leads to cancer is rare. A priori, therefore, it is most doubtful whether a mutational change which is very easily brought about can be an appropriate model for testing for carcinogenic potential. In any case the main purpose of safety tests on environmental chemicals should not be the relatively academic one of detecting carcinogenic potential but the more practical one of pin-pointing agents which constitute real hazards. It is already clear that a number of substances such as caffeine and formaldehyde, which show definite mutagenic activity in bacterial systems, present no detectable carcinogenic hazard for man. 